\title{
Virtue ethics: an approach to moral dilemmas in nursing
}

\author{
E Arries, M.Cur, Ph.D.; M.Phil. (Ethics) \\ School of Nursing, University of Johannesburg
}

\begin{abstract}
Curationis 28(3): 64-72
Nurses are increasingly confronted with situations of moral difficulty, such as not to feed terminally ill patients, whistle blowing, or participation in termination of pregnancy. Most of these moral dilemmas are often analyzed using the principle-based approach which applies the four moral principles of justice, autonomy, beneficence, and nonmalificence. In some instances, consequentialism is considered, but these frameworks have their limitations. Their limitations has to do with a consideration for the interpersonal nature of clinical nursing practice on the one hand, and is not always clear on how to judge which consequences are best on the other hand. When principles are in conflict it is not always easy to decide which principle should dominate. Furthermore, these frameworks do not take into account the importance of the interpersonal and emotional element of human experience. On the contrary, decisionmaking about moral issues in healthcare demands that nurses exercise rational control over emotions. This clearly focuses the attention on the nurse as moral agent and in particular their character
\end{abstract}

In this article I argue that virtue ethics as an approach, which focus of the character of a person, might provide a more holistic analysis of moral dilemmas in nursing and might facilitate more flexible and creative solutions when combined with other theories of moral decision-making. Advancing this argument, firstly, I provide the central features of virtue ethics. Secondly I describe a story in which a moral dilemma is evident. Lastly I apply virtue ethics as an approach to this moral dilemma and in particular focusing on the virtues inherent in the nurse as moral agent in the story.

\section{Introduction}

The purpose of this essay is to discuss virtue ethics as an approach to moral dilemmas in nursing. Nurses, by virtue of their practice is, the members of the health profession who have the most contact with patients. As a result, they are confronted with situations of intense potential moral conflict more often than any other member of the healthcare team. Most of the times, nurses find it difficult to respond in an appropriate way to such situations of moral conflict, as a consequence they can experience intense moral distress. The moral distress experienced by nurses often results from a conflict between a professional duty to care and personal convictions, such as values and beliefs. In this vein, the boundaries between professional obligations and personal convictions of what are right or wrong in the nursepatient interaction become blurred, for example, the recent case of a theatre nurse who appealed against a demand by his/ her employer to assist in surgery to terminate pregnancy. In this case, it is evident that tension exists between the nurse's personal moral convictions and his/her duty to care. It is in such situations that nursing ethics could play a role in providing nurses with guidance on how to behave and address conflicting issues.

We could consider nursing ethics as concerning itself with what is right (good) or wrong (bad) in the nurse-patient interaction. In this vein, nursing ethics revolves around three central concepts: nurse ("self"), patient ("other") and health ("the good") (Rossouw \& Van Vuuren, 2004:3). It is the dynamic balance 
between these three dimensions that determines whether the response by the nurse to a situation of moral distress is ethical or not. At times, the dynamic balance in the nurse-patient interaction becomes so blurred that a choice between equally valid ethical outcomes or ideals, such as health, must be made. If this happens, we say that a moral dilemma has occurred. Generally, health care practitioners approach moral dilemmas based on two broad, divergent and opposing ethical perspectives.

For example, Botes (1997:3) indicates that doctors predominantly base their ethical decisions on a normative approach to ethics such as principalism with some consideration of consequentialism and utilitarianism. This approach uses the four principles of autonomy, justice, beneficience and non-malificence. However, at times when a moral dilemma ensues and these principles are in conflict. it is not always easy to decide which one should dominate. In addition. some consequences might not be that obvious in a moral situation or due to the lack of information and time, it is not always clear how to decide which consequences would be best within the context of the moral dilemma. Even applying the rule of the greatest good for the greatest number of people might posed problems in a healthcare situation where the rights of each and every individual patient are valued. Some nurses might find the aforementioned approaches very disturbing, because they do not accommodate the interpersonal element of nurse-patient interaction. To this effect, nurses often based their ethical decisions on their engagement with the holistic needs of the patient. This approach is associated with the ethics of care (Gilligan's, 1982 in Botes, 1997:3). Within an ethics of care approach to moral dilemmas, the involvement, harmonious relations between a nurse and a patient as well as the needs of other people within every unique ethical situation plays an important role in solving an ethical problem.

On the one hand, it appears that there is virtually no interaction between the two approaches. Differences in power and knowledge between nurses and doctors in the healthcare situation often lead to a situation where doctors plays a dominant role in ethical decisions. This implies that ethical decision-making about moral dilemmas in particular, is based on a principalism approach with some consideration of consequentialism and utilitarianism. This gives rise to a situation where nurses feel they are marginalised and excluded from moral decisions that affect them equally. Nurses are often expected to carry out ethical decisions made by doctors, such as withdrawing life-support or following a do not resuscitate order. Most of the time, they have not been part of these decisions. This gives rise to conflict in the health team since nurses disagree with decisions made by doctors. This often leads to tension among members of the healthcare team, problems of job dissatisfaction and burn-out among nurses.

On the other hand, it seems that both approaches do not consider the dispositions or character of the nurse as a moral agent as an important factor during moral decision-making. In this vein, it seems that ethical decisions about moral dilemmas could be regarded as ineffective, because they give rise to unnecessary mental and physical suffering for patients and their families as well as conflict. Furthermore, the solution to moral dilemmas could be regarded as incomplete, because it does not accommodate the interpersonal nature of the nurse-patient relationship and the emotional elements of human experience.

As a possible solution to this ineffective and incomplete approach to solving moral dilemmas amongst members of the health team, I suggest a virtue ethics approach to moral dilemmas. The word "approach" is not intended to mean a set of rules that will guide a choice between alternatives, but rather a focus on the type of nurses that we ought to be. I think virtue ethics as an approach to moral dilemmas in nursing provide a more holistic analysis of moral dilemmas and facilitate more flexible and creative solutions when combined with a principalist, consequentialist, utilitarian or ethics of care approach to moral decision-making. To advance this argument, I will present the reader with a rationale for a virtue ethics approach to moral decision-making in nursing. In addition, I will look at the nature of virtue ethics, and focus particularly on the central characteristics of virtue ethics, such as the concepts of virtue and virtuousness, the nature of humanbeing and the telos or the good. To illuminate the aforementioned characteristics of virtue ethics and how they could be applied to moral dilemmas in nursing, I will relate it to the story of Martin. I wish to stress that it is not my intention with this article to provide a list of rules to be followed in order to solve a moral dilemma, because many such useful rules or ethical decision-making methods already exist. What is intended here, rather, is to provide the reader with an understanding of how virtues could be applied to illuminate and make moral decision-making so much more meaningful for the people involved.

\section{Rationale for a virtue ethics approach to moral dilemmas in nursing}

Firstly, ethical principles applied during moral decision-making insist on the use of reason only. Reason itself, as I shall indicate later, can be seen as a virtue. In this vein. they require from nurses as moral agents during moral decisionmaking to "bracket" their emotional experiences. In this vein, ethical principles only tells us what action to take and do not consider the holistic human nature of the nurse as a moral agent. People do not work very well without virtues. Virtues are beneficial to human interaction and communication. and to the functioning of human society (Scott, 1995:280). For example, acting only from a sense of duty is insufficient and likely to fail if one does not have personal virtues of dedication. perseverance and . integrity to back it up.

Secondly, according to the Patient Rights Charter (Department of Health, 1999), patients and their significant others have a right to be involved in decision-making. Williams (1998:264) indicates that on the level of society, patients as consumers of health care demonstrate an increased demand for accessibility and interest in hospital processes, such as decisionmaking. In this vein, patients also become increasingly aware of their right to participate in health care decisions impacting on their health. This is especially true when it come to moral decision-making. Worldwide and locally, patients and their family members are increasingly demanding to be involved in decisions about treatment, including the termination or withdrawal thereof (Biley, 1992:414; Avis, 1994; Sainio, Lauri \& Eriksson, 2001:97-98). To this effect, 
moral decision-making based on a paternalistic, materialistic and deterministic way, especially in a pluralistic society does not hold water any longer. Today, patients and their families demand to be empowered in as far as decisions that affect their daily life is concerned. To involved patients and their families in moral decision-making, do not only require for a paradigm shift, but demands certain kinds of dispositions and sensitivity. In other words, it demands certain virtues in order to tolerate differences in opinion that might arise during an ethical situation. Thus, an approach that demands the use of principles in an impartial way is not tolerated let alone fulfilling the expectations of consumers of health care.

Thirdly, nurses who are in constant interaction with patients and their families are important stakeholders to moral decision-making in health care. As independent practitioners they are accountable for their decisions, including moral decisions. Health care has become increasingly complex, and to this effect, the problems with which health care personnel are confronted are complex too. The complex nature of moral problems requires a collaborative approach. For this reasons, it is no longer feasible for doctors as members of a complex and diverse team to assume a dominant position in solving moral dilemmas or making moral decisions and issuing prescriptions on behalf of other team members. A collaborative approach based on rational interaction through dialogue, discourse and moral sensitivity to moral decision-making in nursing is required. Becoming sensitive to different perspectives in moral decision-making in nursing requires certain dispositions of character. In this vein, it appears that virtue ethics as an approach that focuses on the moral character and disposition of the nurse as a moral agent is crucial to any approach to moral decision-making, whether based on principalism, consequentialism or deontology (Kristjansson, 2000: 193-194).

Lastly, for nurses to participate in moral decision-making confidently, it is necessary for them to understand the language, theories and methods of analysis used in ethical discourse. As practitioners of nursing, nurses have a better understanding of nursing care than any other healthcare practitioner.
However, they might sometimes find it problematic to consider ethical issues involved in such situations, let alone participate in decisions regarding what is good for everyone involved in a moral dilemma. In this vein, virtue ethics as an approach to moral dilemmas in nursing can provide important insights for them. Virtue ethics, in effect, proposes a very sophisticated theory of moral development. For this has crucial farreaching implications for the teaching of ethics (Scott, 1995:284).

\section{The nature of Virtue Ethics (VE)}

Virtue ethics refers to one of three major approaches in normative ethics (Rossouw \& Van Vuuren, 2004:58). However, virtue ethics is not a problemsolving or decision-making tool. Virtue ethics can be defined as an approach that emphasises the character and disposition of a person, in contrast to an approach that emphasises duties, rules or principles (deontology), or one that emphasises the consequences of actions (consequentialism). In this vein, virtue ethics emphasises being rather than doing (Magee, 2001:32-33; Scott, 1995:283). Our being, in other words, who we truly are, influences our behaviour. Thus, virtue ethics in nursing can be viewed as an approach of ethical deliberation about the moral character and dispositions of nurses as moral agents that enables them, as virtuous human beings, to fulfil their purpose and function as professional people. In this vein, a description of a person's character and character traits portrays a way of being instead of acting. Character according to Drane (in Davis, Aroskar, Liaschenko \& Drought, 1997:49) refers to the structure of one's personality with special attention to its ethical components. To this effect, one can argue that from one's way of being flows one's way of conducting the business of one's personal and professional life in ways that are identifiable and dependable over time (Davis, Aroskar, Liaschenko \& Drought, 1997:49). A person's character is a source as well as the product of his/ her value commitments and actions. Thus, if we consider ethics as a dynamic view between what can be regarded as right or wrong and revolving around three central concepts, namely "self", "other" and "the good", than virtues, from a virtue ethics perspective, can be seen as the golden thread that binds them together, and virtue ethics as a framework that can help us understand the virtues necessary for moral excellence.

\section{Virtues}

Virtues are some of the most central characteristics of virtue ethics. Virtue ethics as an approach to moral decisionmaking implies that moral conduct assumes good characteristics in a nurse as a moral agent. In this vein, for a nurse to act as a moral agent that advocates on behalf of a patient during moral decisionmaking in order to demonstrate excellence (arete) and behave well in a sustained manner, requires the development of good characteristics or virtues. In its purest form according to Trianosky (1990:336), virtue ethics holds that only judgements about virtue are basic in morality, and that the rightness of actions is always derivative from the virtuousness of traits.

Virtues, from an Aristotelian perspective, can be defined as a characteristic habit of excellence of the soul (Arrington, 1998:71). From a nursing perspective, it implies a characteristic habit that allows the nurse to become a good practitioner who behaves well. The literature on virtue ethics (Arrington, 1998:71-72; McIntyre, 1998:74-76) distinguishes between two kinds of virtues:, those that relate to a person's character and those that relate to a person's intellect. The former is sometimes referred to as "moral virtue" and the latter as "intellectual virtue". Intellectual virtue as a disposition enables a nurse to reason well, while acting in accordance with right reason, requires moral virtue. However, the contrary is also true. For example, a nurse who applies the principle of benevolence, that is the wish to do good for his/her patient, decides to act in direct opposition to a doctor's do not resuscitate (DNR) prescription. Without apparent self- interest, the nurse might feel that the patient is being treated unfairly and thus decide to act on the patient's behalf. In this vein, the nurse demonstrates courage as a virtue. A courageous nurse is capable of free thought and undertakes responsible actions and carries them out, whatever their implications might be. However, in nursing practice, a courageous act cannot always be justified on the basis of being right or of its consequences. Nurses also need to assess the particular circumstances of a situation and demonstrate some common sense. In this 
vein, they have to find the "right balance" between extremes, which Aristotle refers to as vices (Arrington, 1998:76). Thus, Aristotle believed that a virtue lay in the middle of two contrary vices and is described as "choosing the mean between the vice of excess and the vice of deficiency" (Taylor, 2002:63). For example, a nurse demonstrating the virtue of courage chooses a mean state with fear on the one end and confidence on the other. Sometimes nurses are expected to act courageously and speak -out or "blow the whistle" on actions, that are to the detriment of their patients, for example abusing of patients or making false recordings that could endanger the life of critically ill patients. In this vein, nurses ought to be confident and demonstrate a willingness and perseverance to stand -up or speak out for those for whom they cares. Failure to do so would indicate the morally deficient character of a cowardice nurse (Magee, 2001:38; Arrington, 1998:76).

On the contrary, it would also be inappropriate for nurses to act courageously if there was nothing worth acting courageously about, for example in situations where no facts are available or accusations that are purely based on hear-say. Acting on this basis would indicate the morally excessive character of a foolish or foolhardy nurse. Thus, in conclusion, the acts of a courageous nurse are appropriate and relevant to the particular circumstances of a case. Acting wisely in a particular situation of moral difficulty, requires, according to Aristotle (in Magee. 1987:48), the intellectual virtue of practical wisdom (phronesis). Practical wisdom as a virtue enables the nurse as a moral agent to know what action is correct in a specific situation. To this effect, virtues enable the nurse to discover the relevant moral aspects of a moral dilemma and to interpret. judge and evaluate them, and to apply rules, principles and moral theories wisely to a situation in order to resolve the dilemma. Therefore, both the intellectual virtues (practical wisdom) and the moral virtues (virtues of character) are necessary for the realisation of various types of moral obligations in nursing, including dealing with moral dilemmas. Besides the cardinal virtues expounded by ancient Greek philosophers, such as the virtues of courage, temperance, prudence and justice, Botes and Rossouw (1995:26) described reflection. empathy, fairness, honesty, dedication. responsibility and respect for people as virtues for the nurse as a moral agent. In addition, Beauchamp and Childress (2001:32-38) consider the following five virtues as applicable to health professionals: trustworthiness, integrity, discernment, compassion and conscientiousness.

Decision-making about moral issues in health care demands that the health practitioner or the nurse exercise rational control over emotions. The virtues described in the preceding paragraphs are necessary for such rational control, because it takes a so-called mean position between the vices or excess and deficiency. Self-control in situations of moral difficulty is possible if the nurse possesses virtues. In this vein, a nurse who demonstrates these virtues in a balanced form can be seen as a virtuous nurse. Where virtues reflect the characteristic in itself, virtuousness refers to the quality of that virtue, especially when demonstrated in character. Virtuous nurses are ethical nurses, because they have a deep desire to behave well, irrespective of the circumstances.

\section{The purpose of moral decision-making in nursing}

One characteristic of nursing is its purposeful nature. This implies that with their action or interaction, nurses aim to achieve something. In this vein, the aim that nurses wants to achieve must be worth the effort in other words, it must be good. As indicated elsewhere, ethics revolves around three central concepts: the "self", "other" and "good". The good can sometimes mean different things to different people.

In Aristotelian thought, there is a telos or ultimate goal at which all actions of human beings are directed. Aristotle regards this as -eudaemonia, which is sometimes translated as "happiness" or "well-being" (Asby, 1997:34; Hospers, 1997:254; Arrington, 1998:67). However, a particular state of happiness or wellbeing is intended by him. This state of eudaemonia or happiness involves interaction between various facets of life in order to achieve the telos or the highest good. This state of eudaemonia. according to Aristotle, is found in the nature of human kind (Arrington, 1998:67). The nature of human beings for Aristotle is reflected in their function. Thus, for us to understand what eudaemonia is, we need to grasp what the function of human beings is. Our function as human beings is the one thing that distinguishes us from all other creatures in the universe, for example, : our ability to reflect on our actions;; in other words, to think rationally. Therefore, reason is our unique function, our telos in life (Washburn 2003:77). The level of our reason is closely linked to our developmental state. This implies that as much as reason can vary across a continuum, so can our state of happiness. For example, a mentally impaired person: might sometimes be happier than a person whose faculties are fully functional. A person living in the most physically and mentally appalling conditions can still be happy. Therefore. the state of eudaemonia or happiness that Aristotle had in mind is one that was deeply rooted in the joy a person gets from his/her ability to reason, a happiness that is lasting- and worth having. and that makes the person experiencing it flourish.

As stated previously, the purpose of nursing is to promote the health of the patient. Therefore, eudaemonia is sometimes translated as "health" in nursing (Botes \& Rossouw, 1995:24). However, based on our understanding of what eudaemonia means, health in nursing could therefore mean different things for different people. Thus, health for a patient might not mean health for a nurse or any other health professional. This is a profound idea that nurses should consider. Health for a particular patient might be more transcendental rather than literal. Much as it can imply a state of well-being, happiness or feeling physically well- can also be seen from a spiritual point of view. Thus, a virtuous nurse who acts as a moral agent: will have a deep understanding of the nature of human beings and grasp how this could affect a person's moral decisions or behaviour.

\section{Virtues and the role of emotion and motivation}

The association between virtues, emotion and motivation as well as their relevance to moral decision-making are implicit in the following definition of emotion. Emotion is defined as “... felt tendency toward anything intuitively. appraised as good (beneficial), or away. from anything intuitively appraised as bad (harmful). This atraction or aversion is accompanied by a pattern of 
physiological changes organized towards appropriate action. The patterns differ for the different emotions" (http://plato.stanford.edu). The aforementioned definition imply that virtues related to a person's emotions; motivate him/her to do the right thing. According to Plato, Aristotle's teacher, virtues are related to both emotion and will (http://aristotle'sethics.stanford.edu). In this vein, emotion and motivation are important characteristics of virtues (Kristjansson, 2000: 193-195).

For the sake of so-called objectivity in moral decision-making, an ethical approach based on principalism demands that emotions be discarded or bracket during moral decision-making (Edwards, 1996:123). However, as holistic human beings, nurses's emotions and feelings are fundamental to their nursing experience. Their emotions influence their perception of a moral situation of how and what they see as well as the quality or goodness of the circumstances. When challenged with a situation of moral difficulty, nurses are expected to assess and recognises the morally pertinent aspects of the situation, which requires the use of cognitive processes. However, perceiving the ethical nature of a situation does not only involve a cognitive process. Emotions; of a balanced nature- make us sensitive to particular circumstances and help to illuminate the perception we develop about a particular moral situation. In this vein, what we see shapes how and what we experience. Thus, perception and affect are closely related in informing our moral judgements. Therefore, it should not mean that nurses must not consider their emotions during moral decisionmaking, but they should learn how to practise rational control over them. A virtuous nurse will understand the importance of this, because emotions that are over- or under-expressed could indicate a deficient character. Emotions should not be accepted as instinctive unmanageable reactions to moral dilemmas, but as sensitivities that inform our moral judgements (Kristjansson, 2000:194).

\section{Martin's story}

The following story of Martin demonstrates how virtue ethics could be applied to moral dilemmas in nursing.

Martin, a 58 year-old lawyer who an atheist, is admitted to hospital with multiple musculo-skeletal and head injuries after a motor =vehicle accident. After stabilisation in the resuscitation room, he is rushed to the operating theatre to drain a sub-dural hemorrhage and to reduce his fractures. Due to the extent of his injuries, Martin is admitted post-operatively to the critical care unit. Three days after admission to the unit, Martin regains consciousness and the doctors are able to assess the true extent of his injuries. It has been established that Martin is a known leukaemic sufferer who is currently in remission. He also has diabetes mellitus that is well controlled. As a result of his injuries, he has become a quadriplegic. Despite two occasions of being actively resuscitated in the critical care unit, Martin's cognition remained intact. After four weeks in hospital, Martin is miraculously discharged and send home to the care of his family members as his primary care givers.

Two months after his discharge, Martin is readmitted to hospital with pneumonia. In a conversation with his family one month ago, Martin voiced his choice that should if his condition deteriorated no more active resuscitation procedures should be carried out on him as he cannot bear the suffering any longer. His family was in agreement with him as they were also deeply affected by his suffering. Despite his physical disabilities, the nurses described Martin as a "lovely patient to care for". Martin, being aware of his rights as a patient, voiced his choice of not being actively resuscitated to the health care team".

From this story, it is evident that a moral dilemma has occurred. The dilemma involves the moral right of the patient to refuse treatment on the one hand and the nursing team's duty to care on the other hand. For both nurse and patient, the situation results in intense moral conflict, as it seems that a situation with equally right outcomes has arisen. The nurse has a moral duty to promote Martin's well-being or health. To do so, professionally, nurses are expected to balance their -expert professional knowledge and understanding with the preference of their patients. In terms of their professional expectations, nurses ought to work collaboratively with patients, thus informing, guiding, advising and helping them to make appropriate and responsible choices about their health. Factors that influence a person's health status, such as beliefs, cultural background and social circumstances must be taken into consideration. The nurse has to take into consideration the means by which the patient made decisions on the one hand, and ensure that he/she complies with the legal-ethical framework of his/her practice and own convictions on the other hand. In terms of their Professional Code of Conduct and regulations (Muller, 2001:3-8) guiding their practice and informing their decisions, nurses are professionally bound to do good by promoting the health of their patients. After all, they have pledged not only to uphold the legal-ethical and moral traditions of the profession, but also not to discriminate on the basis of race, colour, conviction or religion. In this vein, nurses have committed themselves to act virtuously. In Martin's situation, nurses are required to demonstrate virtues of honesty, caring, trustworthiness and respect.

\section{Virtue ethics: an approach to moral dilemmas in nursing}

Virtue ethics as an approach focuses on the moral character of the moral agent. In the next section, therefore, we shall focus on the patient and the nurse as moral agents in Martin's story.

\section{The patient as moral agent: Martin's story}

A patient's right to refuse health services, including treatment, is a legal reality in South Africa (Department of Health, 1999). In a long discourse on the issues of terminal care, McCartney and Trau (1990:443) indicate that any care that is painful or discomforting to a dying patient may be perceived as burdensome and the individual has an autonomous right to refuse such intervention. The ethical strength of this argument for autonomy is that it is based on moral thought. Furthermore, it has legal precedent in that many judicial decisions have been made in favour of an individual's right to refuse treatment or have treatment ceased. To accept an autonomous decision by a patient, Tschudin (1986:94) is of the opinion that there must be certainty that the individual has accurate information and that all the implications and outcomes of their decision are fully comprehended. From a 
virtue ethics approach, this implies that nurses need to establish what motivated Martin's decision.

It is important for the nurse as a moral agent to establish whether Martin's decision is motivated freely and sincerely by his faith and whether there is no element of coercion from his religious community or indeed his family. If it is proven beyond reasonable doubt that the patient is able to make an autonomous decision about his spiritual taith, then he is competent to make an autonomous decision about his health. In this instance, Martin's cognition has not been impaired by his illness and if all the concerned participants are satisfied that he has an accurate understanding of his situation, they should respect his choices. Martin for example could have chosen to prioritise what he believes is his eternal existence over what is his current quality of physical health. In this vein, recalling Aristotle's ideas on eudaemonia, health is more of a transcendental nature, for example, the patient might have come to terms with his situation and meaning of his life, based on his belief. This might include that he has come to terms with the existential condition about the inescapable nature of death. Thus, considering this, there is clearly an ethical duty on behalf of the nurse to accept his autonomous choice to refuse resuscitation. From a virtue ethics approach, it would be rather morally right of the nurse to respect the faith their patients, including their choices based on their own free will, rather than to violate it. In these circumstances is necessary for nurses to become aware of how this event has affected them, in other words, to become aware of their emotional responses and the virtues required in the situation.

\section{The nurse as moral agent}

After consideration of the facts, as far as this case is concerned, it is important for the nurse as a virtuous moral agent to become aware of the emotions this case has brought on in him/her. Becoming aware of the emotions that the patient's decision has made him/her experience; will illuminate and deepen the nurse's assessment and understanding of the moral nature and significance of the situation, for example, the nurses might feel anxious that the patient will die unnecessarily and even be worried for the unnecessary sorrow his decision might cause for his significant others. In addition, the nurses might feel that the patient has no regard for their professional obligations to promote health. However, they should realise that their view of health is not necessarily the patient's view. The following two arguments against not resuscitating a patient are usually presented by nurses that of the value of life and the possibility of recovery. The former, the value of life, is usually equated with the sanctity and quality of that life. The latter stance, the possibility of recovery, is usually based on a medicalisation of a moral situation.

The argument for the value of life describes life as sacred and of absolute value. Therefore, all efforts should be directed towards its prolongation (Valente \& Trainer, 1998:252). However, some nurses might interpret life as limitless, which is usually based on a particular world view. This means that all heroic technological interventions must be employed as the means to protect life. However, in a pluralistic society, where more than one world view is evident, differences on the value could exist. To this effect, nurses should recognise that life is not limitless and cannot be perpetuated indefinitely no matter how heroic technological interventions are employed to preserve it. Therefore, the principle of the value and sanctity of life does not mean that life must be preserved at all costs, nor does it imply that quantity of life must be maintained over quality of life (Holmes, 1989:834).

Thus, we can conclude that losses in quality of life, considering the variability and subjective nature thereof, could provide strong moral justification for not resuscitating this patient. In this vein, even the impartial use of ethical principles such as autonomy, justice and faimess to evaluate the case; decreases (Fromer, 1981:14). Therefore. a resolution to this moral dilemma can only be made on the basis of a contextually valid moral strategy that combines virtues with sound moral principles to act as guidelines in identifying acceptable moral actions (Kuhse, 1993:38). Thus, it is important for the nurse as a moral agent in this case to reflect on the virtues that would be more relevant and useful in this situation.

In the next paragraphs, the virtues inherent in Martin's case will be identified and discussed. Botes and Rossouw (1995:24-26) identified a list of virtues relevant to nursing. However, in my opinion, from a virtue ethics perspective, one virtue is not necessarily more important than another. It is rather the context of the moral dilemma in my opinion that dictates the virtues to be demonstrated by the nurse as a moral agent. The virtues necessary in Martin's story are care;- respect and integrity justice and courage; reason; and honesty and trust.

\section{Care as a virtue}

There is general consensus among nurses that care is and should be a central characteristic of nursing. Therefore care must be a virtue inherent in the character of a nurse. Noddings (in Botes, 1997:10) distinguishes between natural and ethical care. Natural care refers to situations where people act voluntarily in the interest of others. Ethical care on the other hand. arises from natural care. However, care as a virtue involves an inherent disposition or attitude and is based on a deep sense of responsibility and empathy.

Based on an analysis of acting from the virtue of caring. Van Hooft (1999:200) concludes that caring embraces both thinking right and feeling right, and having the right goal in the context of an ethical practice. It suffuses all aspects of health-care workers and becomes a full and total orientation of their professional being. In this way both their feeling and their thinking will have the quality of caring. Acting from caring. or acting well or virtuously in the health care context. involves sensitive awareness, proper motivation. and rational and evaluative judgement. Accordingly, being a caring nurse is enough to ensure that one will act well (Van Hooft, 1999:200). In this vein. when nurses act from the virtue of care, they will be doing what anyone could judge to be right. By demonstrating sensitivity and empathy in Martin's case regarding his decision from his perspective and understanding one's own emotions and those of others would enable nurses to develop an unbiased view of Martin's decision and communicate an understanding thereof (Wiseman, 1996:1 165; Barker, 2000:332). Thus, a virtuous nurse who approaches Martin's situation from a virtue of carewill view his decision with empathy and a deep sense of responsibility. In so doing, the nurse as a virtuous moral agent realises the courage Martin demonstrates, which might in turn 
provoke feelings of respect and admiration.

\section{Respect and integrity as virtues}

In his third Categorical Imperative, Kant stipulates that one should never treat people as a means to achieve an end, but as ends in themselves (Arrington, 1998:104). This implies that we should treat people as human beings with respect. To demonstrate respect is to demonstrate a sensitivity to the differences in the views that people as human beings might hold and learn to understand them even if we disagree. As human beings, this also implies that we should respect the autonomy of others. The ethical strength of this argument for autonomy is that it is based on moral thought on the one hand and that it has legal precedent on the other, because many judicial decisions have been made in favour of people's right to express themselves freely, and to refuse treatment or have treatment ceased (National Health Act, 2004). In Martin's case it would be the morally right thing for the nurse to respect the faith of the patient and his choices, which he has made based on his own free will, rather than to violate them. Violating the faith of the patient might jeopardises the inherent trust relationship between nurse and =patient, which might have detrimental effects for both as moral agents.

Integrity means being faithful to one's commitments; it focuses on nurses as people and their dedication to their patients (Gaul, 1995:133). Thus focus of integrity is on the nurse-patient relationship. Nurses with integrity take the quality of patient care seriously, not only because they owe it them, but also because they judge themselves in meeting this standard. Integrity also demands that they speak up on behalf of the patient when issues of incompetence or immoral actions against patients by fellow healthcare workers arise. Acting based on integrity in Martin's caserequires the nurses to support his decision or, if they do not, to ensures that patient care is transferred to another qualified caregiver. Integrity does not requires nurse's who are ethically opposed to, for example, the patient's "right to die" decisions to participate in planning or carrying out a treatment plan. However, it does require that continuity of care be ensured (Gaul, 1995:134).
Justice and courage as virtues

Justice can be seen as a principle and as a virtue. Justice as a principle implies fairness and equality. Justice as a virtue enables the nurse to have an awareness of, and a special concern for, the vulnerability of a patient. Therefore, justice can be expressed in concrete actions, i.e. when the nurse-s in Martin's situations understands his vulnerability and then develop the need to act in his best interests. From this perspective, justice is not only a matter of fairness in the distribution of nursing care and health resources, but also what Pellegrono and Thomasa (1993) call "loving justice" (Lutzen \& Da Silva, 1996:208). The virtue of "loving" justice can also be related to the virtue of benevolence, which implies a wish to do good for other (Edwards, 1996:68-69).

Considering the case of Martin, if the nurse wishes to demonstrate the virtue of a "loving justice" he/she will feel the need to act on behalf of the patient, if he/ she perceives the latter to be unfairly treated. In other words, what motivates nurses is the intention to do good or what they as virtuous moral agents perceives to be in the best interests of the patient. For example, after a consideration of all the facts and the consequences, nurses might be convinced that not resuscitating the patient might be in the patient's best interest, and in response to this they voice their thoughts to the rest of the ethical decision-making team. In this way, the nurses demonstrates some courage in advocating on behalf of the patient, even if it sometimes means upsetting other team members who might feel that the responsibility is solely that of the doctors. To this end, the nurse demonstrates courage by speaking out and questioning existing practice.

A courageous nurse is someone who is capable of free thought, undertakes responsible actions and carries them out. However, acting courageously cannot always be justified as right on the basis of its consequences, for example when driven by compassion. Other normative aspects need to be considered (Lutzen \& Da Silva, 1996:209). In this regard, it is not the consequence of the action that is the guiding principle, but the virtuous conscience and the trust the patient has in the nurse to advocate of his behalf that should motivate the nurse (MacIntyre, 1998:57). To demonstrate justice as a virtue implies exercising practical wisdom (intellectual virtue), which is motivated by the virtues of character (moral virtues) to decide how to act in order to make the best possible decision. Thus, the nurses'virtues enable them not only to do what is right, as in the case of applying rules and law, but also to do the right thing right. Thus, justice as a virtue also implies respect for the patient's integrity or dignity, which is not only a matter of being fair or just Lutzen \& Da Silva, 1996:209.

\section{Reason as a virtue}

Nurses are often accused of responding to ethical situations in an emotional and irrational way. This is claimed by Botes (1997:13) to be the main reason why doctors are intolerant of including them in moral clinical decision-making. Thus, the intolerance is not aimed at the approach, e.g. virtue ethics or the ethics of care, but at the way in which it is operationalised by nurses. This intolerance will probably continue until nurses apply virtue ethics in a rational way. However, reason does not only imply the use of abstract rules and principles to make decisions or solve problems, but also certain dispositions. Reason must be supported by virtues, but virtues alone are not sufficient to make a moral choice. Therefore, nurses as moral agents also needs a certain disposition to use their reason. Reason as a virtue in Aristotelian terms implies a certain kind of excellence (arête) of the soul. Like Plato, Aristotle is of the opinion that the excellence of reason is wisdom (Arrington, 1998:54). This implies that wisdom is the virtue of reason. MacIntyre (1984:150) also states that “... the exercise of the virtues requires ... a capacity to judge and to do the right thing in the right place at the right time in the right way. The exercise of such judgement is not a routinizable application of rules". Therefore, nurses as moral agents in Martin's case must demonstrate practical wisdom to decide how to respond to a situation. In other words to do what is right in this case, and that is to respect the choices Martin has made.

Plato was of the opinion that the excellence (or arête in Aristotelian terms) of reason is wisdom (Arrington, 1998:54). This implies that wisdom is the virtue of reason. In this vein, MacIntyre (1984:150) 
states that "... the exercise of the virtues requires ... a capacity to judge and to do the right thing in the right place at the right time in the right way. The exercise of such judgement is not a routinizable application of rules".

\section{Honesty and trust as virtues}

Honesty is one of the cornerstones of the nurse-patient relationship. Honesty refers to the quality of not lying, cheating, stealing or being insincere, but qualities of truth, sincerity and reliability (Botes \& Rossouw, 1995:25). Every patient has the right to honest information about the nature of their health status. Honesty is a pre-condition for a trust relation. Patients often reveal their deepest and most personal concerns and problems with nurses. This means that patients trust nurse, thus confiding their private vulnerabilities. For example, Martin's vulnerable state,leaves him with almost no option but to trust the nurses to honour and respect his choices. However, a virtuous nurse will realise this profound dependence of the patient and knows not to exploit them so as not to cause them harm. Trust can be lost if the nurses decide to violate the faith of the patient. Trust must be earned, because if there is distrust on the part of the patient, it could be because the nurses fail to perform what is necessary for the patient. Patients rely on the nurses' moral character and competence and trust that nurses will behave well. The least that nurses as moral agents acting in the situation can do is not to violate this trust (Lutzen \& Da Silva. 1996:207).

\section{Conclusion}

In this essay, I argued that aspects of virtue ethics have important insights to offer ethical thought in nursing. Aristotle's theory of the virtues proposes a sophisticated theory of moral development. It also has much to say to others regarding people's disciplines, such as health professionals, educationalists and others. The idea of being good is important, and to be good, one must look and work at one's character and develop certain character traits, called virtues. The virtues are a somewhat neglected part of morality in nursing. What is clear from the analysis is that acting from virtue involves an awareness of one's telos and nature, proper motivation and rational moral judgement. Living a moral life is not simply a matter of following moral rules and of learning to apply these rules to specific situations. Living a moral life is also a matter of trying to determine the kind of nurses we should be or ought to be, and attending to the development of character within ourselves. Thus, the aspects of virtue ethics discussed in this essay urges us as nurses to pay attention to our habits of character and to develop these, in order to act in a moral way with our patients. In other words, living a just life, one filled with happiness both for our patients and ourselves. In conclusion, virtue ethics as an ethical theory gives priority to virtuous character of nurses as moral agents. A virtuous nurse is one who is a self-lover and who enjoys most the exercise of his/her abilities to think rationally. This enjoyment guides them as moral agents in determining what actions are appropriate in patient care situations. A virtuous nurse despises the pleasures associated with common vices, such as greed and selfishness. A virtuous nurses' moderate and balanced emotional disposition is not viewed as an aspect of his/her character that needs to be controlled externally by rules, rather, his/her judgements are informed and guided by rational powers or practical wisdom.

\section{REFERENCES}

ARRINGTON, RL 1998: Western ethics: An historical introduction. Massachusetts: Blackwell Publishers

ASHBY, W EDS. 1997: A comprehensive history of Western ethics: What do we believe? New York: Prometheus Books.

AVIS, M 1994: Choice cuts: An exploratory study of patients' view about participation in decision-making in a day surgery unit. International Journal of Nursing Studies. 31:289-298.

BARKER, P 2000: Reflections on caring as a virtue ethic within an evidence-based culture. International Journal of Nursing Studies. 37: 329-336.

BEAUCHAMP, T \& CHIIDRESS, J 2001: Principles of bio-medical ethics. Fifth edition. Oxford: Oxford University Press.

BILEY, F 1992: Some determinants that affect patient participation in decisionmaking about nursing care. Journal of Advanced Nursing. 17:414-421.
BOTES, AC \& ROSSOUW, G 1995: The reconstruction of virtue based ethics in nursing. RAUCUR. 1(2), Nov. 1995:19-26.

BOTES, AC: The ethics of care and of justice in ethical decision-making in the health team: Inaugural address presented on 27 August 1997. Johannesburg: Rand Afrikaans University.

DAVIS, AJ; AROSKAR, MA; LIASCHENKO, J \& DROUGHT, TS 1997: Ethical dilemmas in nursing practice. Fourth Edition. New Jersey: Prentice-Hall, Inc.

DEPARTMENT OF HEALTH (SOUTH AFRICA) 1999: A Patients' Right Charter. Pretoria: Department of Health.

DRANE, JF: Character and the moral life (In: Davis, AJ; Aroskar, MA; Llaschenko, J \& Drought. TS 1997: Ethical dilemmas in nursing practice. Fourth Edition. New Jersey: Prentice-Hall, Inc).

EDWARDS, SD 1996: Nursing ethics: a principle-based approach. London: MacMillan

FROMER, MJ 1981: Ethical issues in health care. St Louis: Mosby.

GAUL, AL 1995: Care: An ethical foundation for critical care nursing. Critical Care Nurse. June 1995:131-135.

GILLIGAN, C 1982: In a different voice: Psychological theory and women's development. Cambridge: Harvard University Press.

HOLMES, CA 1989: Health care and the quality of life: A review. Journal of Advanced Nursing. 14: 834-837.

HOSPERS J 1997: An introduction to philosophical analysis. Fourth edition. London: Routledge.

KUHSE, H 1993: Caring is not enough: Reflections on a nursing ethics of care. The Australian Journal of Advanced Nursing. 11 (1): 38-43.

KRISTJANSSON, K 2000: Virtue ethics u and emotional conflict. American Philosophical Quarterly. 37(3), July 2000:193-207.

LUTZEN, K \& DA SILVA, AB 1996: The role of virtue ethics in psychiatric nursing. 
Nursing Ethics. 3(3): 202-211.

MACINTYRE A 1984: After virtue. Second edition. Notre Dame, IN: University of Notre Dame Press.

MACINTYRE A 1998: A short history of ethics. London: Routledge.

MAGEE B 2001: The story of philosophy. London: Dorling Kindersley Limited.

MCCARTNEY, JJ \& TRAU, JM 1990: Cessation of the artificial delivery of foods and fluids: Defining terminal illness and care. Death Studies, 14: 443-447.

MULLER, ME 2001: Nursing Dynamics. Third edition. Sandown: Heinemann.

PELLINGRINOED \& THOMASMADC 1993: The virtues in medical practice. New York: Oxford University Press.

ROSSOUW D \& VAN VUUREN L 2004: Business ethics. Third edition. Cape Town: Oxford University Press for Southern Africa.

SAINIO, C; LAURI, S \& ERIKSSON, E 2001: Cancer patients' views and experiences of participation in care and decision-making. Nursing Ethics. 8(2):97113.

SCOTT, PA 1995: Aristotle, nursing and health care ethics. Nursing Ethics. 2(4): 279-285.

SOUTH AFRICA (REPUBLIC). National Health Act (Act 61 of 2003). Pretoria: Government Printer.

TAYLOR R 2002: An introduction: Virtue ethics. New York: Prometheus Books,

TRIANOSKY, G 1990: What is virtue ethics all about? American Philosphical Quarterly. 27(4), October 1990:335-344.

TSCHUDIN, V 1986: Ethics in nursing: The caring relationship. Oxford: Butterworth Heinemann.

VAN HOOFT, $S$ 1999: Acting from the virtue of caring in nursing. Nursing Ethics, 6(3): 189-201.

WASHBURN P (ED) 2003: The many faces of wisdom. Great philosophers' visions of philosophy. New Jersey: Upper Saddle River.
WISEMAN, T 1996: A concept analysis of empathy. Journal of Advanced Nursing. 23:1162-1167.

\section{INTERNETSOURCES}

Aristotle's ethics. Stanford Encyclopedia of Philosophy. (http:// aristotle'sethics.stanford.edu). Accessed on 04 April 2004.

Plato's ethics: An overview. Stanford Encyclopedia of Philosophy. (http:// plato.stanford.edu). A.ccessed on 04 April 2004. 